\title{
Evaluation of adrenal reserve in patients with differential thyroid cancer receiving thyroid hormone suppression therapy- case-control comparative study
}

\section{Muhammet Cuneyt Bilginer ( $\nabla$ cuneytbilginer@hotmail.com )}

Karadeniz Technical University Faculty of Medicine: Karadeniz Teknik Universitesi Tip Fakultesi https://orcid.org/0000-0002-7652-7648

\section{Abbas Ali Tam}

Ankara Yıldııım Beyazıt Üniversitesi Tıp Fakültesi: Ankara Yildirim Beyazit Universitesi Tip Fakultesi

\section{Sevgul Faki}

Ankara City Hospital: Ankara Sehir Hastanesi

\section{Nagihan Bestepe}

Ankara City Hospital: Ankara Sehir Hastanesi

\section{Fatma Dilek Dellal}

Ankara City Hospital: Ankara Sehir Hastanesi

\section{Didem Ozdemir}

Ankara Yıldııım Beyazıt Üniversitesi Tıp Fakültesi: Ankara Yildirim Beyazit Universitesi Tip Fakultesi

Oya Topaloglu

Ankara Yıldııım Beyazıt Üniversitesi Tıp Fakültesi: Ankara Yildirim Beyazit Universitesi Tip Fakultesi

\section{Reyhan Ersoy}

Ankara Yıldırım Beyazıt Üniversitesi Tıp Fakültesi: Ankara Yildirim Beyazit Universitesi Tip Fakultesi

\section{Bekir Cakir}

Ankara Yıldııım Beyazıt Üniversitesi Tıp Fakültesi: Ankara Yildirim Beyazit Universitesi Tip Fakultesi

\section{Research Article}

Keywords: Thyroid cancer, Hyperthyroidism, Thyrotoxicosis, Adrenal insufficiency, ACTH stimulation test

Posted Date: November 3rd, 2021

DOI: https://doi.org/10.21203/rs.3.rs-1043425/v1

License: (9) This work is licensed under a Creative Commons Attribution 4.0 International License.

Read Full License 


\section{Abstract \\ Background}

Patients with differentiated thyroid cancer (DTC) are exposed to subclinical exogenous hyperthyroidism for the suppression of thyroid-stimulating hormone (TSH). In this study, we aimed to evaluate the adrenal reserve in DTC patients receiving suppression therapy.

\section{Materials and Methods}

The study included 55 DTC patients on suppression therapy and 32 healthy volunteers. Basal serum cortisol of all participants and adrenocorticotropic hormone (ACTH) of the patient group were measured. A standard-dose ACTH test $(0.25 \mathrm{mg})$ was performed in patients with a basal cortisol $<14.5 \mathrm{mcg} / \mathrm{dL}$.

\section{Results}

In the patient group, TSH was lower, free thyroxine (fT4) was higher, and free triiodothyronine (fT3) was similar to those of the control group $(p<0.01, p<0.01, p=0.140$, respectively). The serum cortisol of the patient group was significantly lower than the control group $(12.14 \pm 5.12 \mathrm{mcg} / \mathrm{dL}$ vs $18.00 \pm 5.56$ $\mathrm{mcg} / \mathrm{dL}, \mathrm{p}<0.001) .34$ (61.8\%) patients with DTC had a basal cortisol $<14.5 \mathrm{mcg} / \mathrm{dL}$. Prolonged TSH suppression ( $\geq 5$ years vs $<5$ years) was associated with lower basal cortisol $(7.46 \pm 2.63 \mathrm{mcg} / \mathrm{dL}$ vs $9.48 \pm 2.65 \mathrm{mcg} / \mathrm{dL}, \mathrm{p}=0.022)$. The ACTH stimulation test showed that $2(5.8 \%)$ patients had a cortisol response $<18 \mathrm{mcg} / \mathrm{dL}$. The rate of adrenal insufficiency was $3.6 \%$ in DTC patients. A moderate negative correlation was found between ACTH and fT3 of patients with low basal cortisol $(r=-0.358, p=0.038)$

\section{Conclusion}

Patients with DTC receiving TSH suppression therapy are at risk for adrenal insufficiency. The duration and severity of suppression might increase this possibility. Dynamic testing with synthetic ACTH can be used to reveal insufficient cortisol response in case of clinical suspicion.

\section{Introduction}

Thyroid carcinoma is the most common endocrine malignancy [1]. It is classified as differentiated thyroid cancer (DTC) if it originates from the follicular epithelium [2]. In some patients, DTC treatment involves the long-term administration of a supraphysiological dose of levothyroxine after total thyroidectomy and radioactive iodine (RAI) treatment. [3]. The rationale behind thyroid-stimulating hormone (TSH) suppression is based on data showing that TSH stimulates thyroid cell proliferation and thyroglobulin production [4]. Therefore, TSH suppression prevents the growth of residual neoplastic tissues and ensures the prevention of tumor recurrences [3]. As a result, intermediate and high-risk patients with DTC 
may be exposed to iatrogenic thyrotoxicosis for a long time [3]. Many studies have been conducted on the negative effect of hyperthyroidism on the hypothalamic-pituitary-adrenal (HPA) axis [5, 6]. It is suggested that thyrotoxicosis increases the work capacity of the adrenal glands to compensate for the increased cortisol destruction, and causes decreased cortisol response to related stimuli [6, 7]. The enlargement of the adrenal glands detected on computed tomography in hyperthyroid patients was thought to be related to the hyperactivity of the HPA axis [6]. The effect of subclinical iatrogenic thyrotoxicosis on the HPA axis in patients with thyroid cancer has never been studied before. The aim of this study was to evaluate the adrenal reserve in patients diagnosed with thyroid cancer and receiving suppression therapy using levothyroxine.

\section{Materials And Methods Participants}

Fifty-five patients with thyroid cancer and 32 healthy volunteers were included. Patient group inclusion criteria were determined as having DTC for at least 1 year and a TSH value of $<0.5 \mathrm{ulU} / \mathrm{mL}$. Exclusion criteria for all participants were having primary or secondary adrenal insufficiency, Cushing syndrome, recent steroid use (last 6 months), history of non-thyroid malignancy, diabetes mellitus, pregnancy, diseases that might affect cortisol-binding globulin level (cirrhosis, nephrotic syndrome), autoimmunityrelated diseases (Hashimoto's disease, Graves' disease, celiac disease), and being older than 65 years or younger than 18 years of age. Sociodemographic data, clinical findings, histopathology results, and RAI dose received by the patients were retrieved from the patient files. The total weekly levothyroxine dose was calculated by adding the daily doses of the patients who received varying daily doses of levothyroxine. Local ethical committee approval was obtained, and the study was conducted in accordance with the ethical standards of the Declaration of Helsinki.

\section{Laboratory evaluation}

Basal cortisol levels of all the participants and adrenocorticotropic hormone (ACTH) levels of the patient group were measured. Blood was taken at 08:00 in the morning for basal cortisol and ACTH measurements. For ACTH measurements, plasma samples were kept in frosted silicon glass tubes containing ethylenediaminetetraacetic acid (EDTA) and stored below $-20^{\circ} \mathrm{C}$ until transfer. Serum cortisol was measured using an immunometric assay, and intra and interassay coefficients of variability (CVs) were $3.0 \%$ and $4.7 \%$, respectively. ACTH was measured using radioimmunoassay; the mean intra and interassay CVs were $3.8 \%$ and $7.2 \%$, respectively. Normal levels of cortisol and ACTH defined by the manufacturers were 6.7-22.6 mcg/dl and $<46 \mathrm{ng} / \mathrm{L}$, respectively. Serum TSH, free triiodothyronine (fT3), free thyroxine (fT4), glucose, alanine aminotransferase (ALT), triglyceride, low-density lipoprotein (LDL), and high-density lipoprotein (HDL) levels were measured using chemiluminescence methods (Immulite 2000, Diagnostic Products Corp., Los Angeles, California and UniCel DXI 800, Beckman Coulter, Brea, California). Normal ranges for serum TSH, fT3, fT4, glucose, ALT, triglyceride, LDL, and HDL were 0.27$4.2 \mathrm{ulU} / \mathrm{mL}, 1.57-4.71 \mathrm{pg} / \mathrm{mL}, 0.61-1.12 \mathrm{ng} / \mathrm{dL}, 70-100 \mathrm{mg} / \mathrm{dL}, 0-45 \mathrm{U} / \mathrm{L}, 50-150 \mathrm{mg} / \mathrm{dL},<160$ 
$\mathrm{mg} / \mathrm{dL}$, and $45-65 \mathrm{mg} / \mathrm{dL}$ respectively. Patients with a cortisol level of $<14.5 \mathrm{mcg} / \mathrm{dL}$ were defined to have low basal cortisol, and ACTH stimulation test was performed for suspected adrenal insufficiency in these patients [8].

\section{Adrenocorticotropic hormone stimulation test}

It is the standard screening test for the diagnosis of primary adrenal insufficiency. The ACTH stimulation test was performed by the intravenous administration of $0.25 \mathrm{mg} \mathrm{ACTH}$ (Synacthen ${ }^{\circledR}$, Novartis). Cortisol was measured at 0,30 , and 60 minutes after ACTH injection in the morning. If the serum cortisol concentration was $\geq 18 \mathrm{mcg} / \mathrm{dL}$ at the 30 th or 60 th minutes, the diagnosis of primary and secondary adrenal insufficiency was excluded [8-10].

\section{Statistical analysis}

All statistical analyses were performed using the SPSS 15.0 software package (SPSS Inc., Chicago, IL, USA). Results of descriptive analyses are presented as mean \pm standard deviation for normally distributed variables, median and range (minimum-maximum) for non-normally distributed variables, and number of cases and percentages (\%) for nominal variables. Categorical variables were evaluated using the Pearson's chi-square test. Wilcoxon test and paired t-test were used to compare means among nonnormally and normally distributed dependent variables, respectively. For non-normally distributed independent variables, Mann-Whitney $U$ and Kruskal-Wallis tests were performed as applicable. Spearman's analysis was used to determine correlations between interval variables that were not normally distributed. The relationship between normally distributed independent variables was examined using the Pearson's correlation test, and the relationship between non-normally distributed independent variables was examined. A p value $<0.05$ indicated statistical significance.

\section{Results}

The patient group consisted of $50(90.9 \%)$ women and $5(9.1 \%)$ men and the control group consisted of $27(84.4 \%)$ women and $5(15.6 \%)$ men $(p=0.357)$. The mean age of the patient group was $44.27 \pm 10.81$ years, and the mean age of the control group was $42.65 \pm 13.79$ years $(p=0.546)$. Histopathological diagnosis was papillary thyroid cancer in 51 (92.7\%) and follicular thyroid cancer in 4 (7.3\%) patients. The median disease duration was 33 months (12-107 months), mean levothyroxine dose was $949.72 \pm$ $182.09 \mathrm{mcg} /$ week, and RAl dose was $114.45 \pm 32.80 \mathrm{mci}$. There was no difference between the groups in terms of body mass index $\left(\mathrm{kg} / \mathrm{m}^{2}\right)$, fasting glucose, ALT, triglyceride, LDL, HDL, and fT3 levels (Table-1). In the patient group, TSH was significantly lower and free T4 was significantly higher compared to those of the control group ( $p<0.001$ for each) (Table-1). DTC patients had significantly lower cortisol than control group $(12.14 \pm 5.12 \mathrm{mcg} / \mathrm{dL}$ vs $18.00 \pm 5.56 \mathrm{mcg} / \mathrm{dL}, \mathrm{p}<0.001)$ The mean ACTH level of the patient group was $21.49 \pm 11.77 \mathrm{ng} / \mathrm{L} .34(61.8 \%)$ patients had a basal cortisol level of $<14.5 \mathrm{mcg} / \mathrm{dL}$ (low basal cortisol), whereas 21 (38.2\%) had a basal cortisol level of $\geq 14.5 \mathrm{mcg} / \mathrm{dL}$ (normal basal cortisol). Rate of patients with low basal cortisol was higher in the patient group compared to the control group $(p=0.006)$. ACTH stimulation test performed in the patients with low basal cortisol showed a mean 
cortisol level of $11.78 \pm 4.27 \mathrm{mcg} / \mathrm{dL}$ at the 0 th minute, $23.73 \pm 5.96 \mathrm{mcg} / \mathrm{dL}$ at the 30 th minute, and $27.48 \pm 6.42 \mathrm{mcg} / \mathrm{dL}$ at the 60th minute. There were $2(5.8 \%)$ patients with a cortisol response of $<18$ $\mathrm{mcg} / \mathrm{dL}$ at the 30th and 60th minutes (Table-2). Of all the patients with DTC, the rate of unresponsiveness to the ACTH stimulation test was $3.6 \%$.

Among patients with low basal cortisol, those with a $<5$-year duration of suppression had significantly higher basal cortisol compared to those with a $\geq 5$-year duration of suppression $(9.48 \pm 2.65 \mathrm{mcg} / \mathrm{dL}$ vs $7.46 \pm 2.63 \mathrm{mcg} / \mathrm{dL}, \mathrm{p}=0.022$ ). The mean basal ACTH level did not differ with regard to disease duration $(17.42 \pm 7.79 \mathrm{ng} / \mathrm{L}$ in those with $<5$ years and $14.71 \pm 6.12 \mathrm{ng} / \mathrm{L}$ in those with $\geq 5$ years supression, $\mathrm{p}=$ 0.320) (Table-3). In patients with low cortisol, basal cortisol and ACTH were not correlated with levothyroxine weekly dose and exposed RAI dose (Table-4). In addition, no correlation was found between basal cortisol level and TSH, fT4, and fT3 levels. While basal ACTH was not correlated with TSH and fT4 levels, a moderate negative correlation was found between basal ACTH and fT3 $(r=-0.358, p=0.038)$

\section{Discussion}

Studies examining the effect of elevated thyroid hormone levels on adrenal reserve focus on patients with Graves' disease or endogenous hyperthyroidism [6,11-16]. To the best of our knowledge, no study has been conducted on the effect of TSH suppression therapy on the adrenal reserve in patients with DTC. This is the first study in the literature showing this relationship. Few studies on the adverse effects of iatrogenic thyrotoxicosis on the HPA axis were conducted using animal models but these effects are not yet evaluated in humans $[5,17]$. In the present study, we initially screened our participants with a morning basal cortisol measurement. Different results have been presented for morning basal cortisol levels in patients with hyperthyroidism. In a study by Mishra et al., patients with endogenous hyperthyroidism were found to have a basal cortisol level similar to that of the individuals in the control group [11]. In contrast, Nascif et al. found it to be higher compared to that of the controls [16]. In another study, basal cortisol levels of patients were lower in the hyperthyroid phase compared to those in the euthyroid phase [6]. In the present study, basal serum cortisol of patients with DTC was significantly lower than those of the control group. In addition, rate of patients with low basal cortisol was significantly higher in the patient group than in the control group. The reason for lower cortisol in our patient group might be longer duration of suppression in our study compared to previous studies. Supporting our study, Tsatsoulis et al showed that steroidogenesis was not increased and even significantly suppressed in case of chronic administration of high-dose thyroxine in thyroidectomized male rats [14].

We think that the results of our patient group reflect the chronic effects of thyrotoxicosis on the adrenal glands. Consistent with this opinion, we found that the basal cortisol level was significantly lower in patients whose suppression treatment duration exceeded 5 years. Although serum ACTH was lower in patients with a longer disease duration, this finding was not statistically significant. Prolonged suppression periods were also shown to be associated with thyroid storm due to reduced adrenocortical reserves [18]. This is explained by the fact that when hyperthyroidism becomes chronic, the adrenal 
glands work at maximum capacity to keep up with the increased metabolic destruction of cortisol, depleting their reserves [5].

In case of exogenous subclinical hyperthyroidism, serum fT3 levels usually lie in the middle of the reference limits, and an increased fT3 level during levothyroxine therapy is considered to be indicative of overt iatrogenic hyperthyroidism [4]. fT3 is thought to be the best parameter to monitor TSH suppression therapy in patients with DTC [4]. In our study, we found a significant negative correlation between basal ACTH and fT 3 levels. In other words, we found that as fT3 increased in patients, serum ACTH level was further suppressed. This result supports the view that besides the duration of the hyperthyroid state, its severity may also be an important factor in determining the functional capacity of the adrenal glands [5]. Goswamin et al. found that ACTH and cortisol response were significantly lower in patients with high serum fT3 levels [6]. In addition, it was suggested that in case of experimentally induced hyperthyroidism, changes in the HPA function become more pronounced as the severity of thyroid dysfunction increases $[5,19]$. Agbaht $\mathrm{K}$ et al. found that the cortisol cycle increased as serum thyroid hormone levels increased [13].

In the present study, we performed the 250-mcg-standard, high-dose ACTH stimulation test to screen for adrenal insufficiency in patients with thyroid cancer based on the Endocrine Society Clinical Practice Guideline [20]. We found that the rate of patients having an inadequate cortisol response in the ACTH test was $5.8 \%$, and the rate of adrenal insufficiency was $3.6 \%$ among all the patients. The prevalence of secondary adrenal insufficiency is estimated to be between 150-280/million [21]. Accordingly, we can estimate that patients with DTC receiving suppression therapy are at a higher risk for adrenal insufficiency compared to the general population. In a study evaluating a heterogeneous group in terms of hyperthyroidism in Turkey, $10 \%$ of the patients showed an inadequate response in the ACTH stimulation test [12]. Mishra et al. reported that inadequate cortisol response was observed in $34.5 \%$ of the hyperthyroid patients evaluated with $250 \mathrm{mcg}$ ACTH and $48.3 \%$ of the patients evaluated with $1 \mathrm{mcg}$ ACTH [11]. Tsatsoulis et al. showed that adrenal cortisol responses to low-dose ACTH stimulation were reduced after dexamethasone administration in patients with severe thyrotoxicosis [14]. Goswamin et al. evaluated the patients in hyperthyroid and euthyroid phases and obtained a $22 \%$ subnormal response to 250-mcg ACTH in the hyperthyroid phase [6]. We believe that our study group is not suitable for comparison with other studies in the literature in terms of the rate of adrenal insufficiency. This is because the patient group and duration of illness in our study are different from those in other studies. Accompanied autoimmune adrenalitis was reported in $5.7 \%$ of patients with Graves' disease $[22,23]$. However, it is difficult to say whether this is purely because of the hyperthyroid status or concomitant adrenal insufficiency due to autoimmunity. In the present study, we eliminated this problem by not including those with a history of Graves' and autoimmune thyroid diseases.

In conclusion, patients with DTC receiving suppression therapy are at a risk for adrenal insufficiency. In addition, it should be kept in mind that the findings of thyrotoxicosis may mask the findings of adrenal insufficiency. This possibility increases as the duration of suppression therapy and the severity of 
thyrotoxicosis increases. Furthermore, dynamic testing should be performed in stress conditions with an emphasis on the HPA axis and in cases of clinical suspicion.

\section{Limitations}

The main limitation of this study is its single-center design. Furthermore, we screened the control group only using basal cortisol measurements. The cortisol level of these healthy volunteers was above 10 $\mathrm{mcg} / \mathrm{dl}$ and there was no clinical finding suggestive for adrenal insufficiency. Therefore, we did not measure ACTH levels and perform ACTH stimulation test in this group. In addition, it is suggested by some authors that this dose of ACTH is supraphysiological and $1 \mathrm{mcg}$ ACTH should be used for the diagnosis of adrenal insufficiency [24]. However we used $250 \mathrm{mcg}$ ACTH stimulation test for this purpose since it is still the standart test recommended by Endocrine Society Clinical Practice Guideline [20]. Performing subgroup analyses with a larger patient group and comparing different test protocols might help to clarify effect of suppression treatment on adrenal reserve in DTC patients.

\section{Declarations}

Funding No funding was received for conducting this study.

\section{Compliance with ethical standards}

Conflict of interest The authors declare no relevant conflicts of interest.

Ethical approval The study protocol was approved by Ankara Yıldırım Beyazıt University and complied with the principles of the Declaration of Helsinki

Consent for publication Patients signed informed consent regarding publishing their data.

\section{References}

1. S.A. Hundahl, I.D. Fleming, A.M. Fremgen, H.R. Menck, A National Cancer Data Base report on 53,856 cases of thyroid carcinoma treated in the U.S., 1985-1995. Cancer. 83(12), 2638-2648 (1998)

2. M.E. Cabanillas, D.G. McFadden, C. Durante: Thyroid cancer. Lancet. 3;388(10061): 2783-2795 (2016)

3. B.R. Haugen, E.K. Alexander, K.C. Bible, G.M. Doherty, S.J. Mandel et al., 2015 American Thyroid Association Management Guidelines for Adult Patients with Thyroid Nodules and Differentiated Thyroid Cancer: The American Thyroid Association Guidelines Task Force on Thyroid Nodules and Differentiated Thyroid Cancer. Thyroid. 26, 1-133 (2016)

4. B. Biondi, D.S. Cooper, Benefits of thyrotropin suppression versus the risks of adverse effects in differentiated thyroid cancer. Thyroid. 20(2), 135-146 (2010) 
5. E.O. Johnson, T.C. Kamilaris, A.E. Calogero, P.W. Gold, G.P. Chrousos, Experimentally-induced hyperthyroidism is associated with activation of the rat hypothalamic-pituitary-adrenal axis. Eur. J. Endocrinol. 153, 177-185 (2005)

6. R. Goswami, N. Kochupillai, Adrenocortical reserves in patients with Graves' disease. Eur. J. Endocrinol. 144(1), 85 (2001)

7. S.O. Nascif, P. Molica, S.R. Correa-Silva, M.R. Silva, A.M. Lengyel, Ghrelin and GHRP-6-induced ACTH and cortisol release in thyrotoxicosis. Pituitary. 12, 315-321 (2009)

8. Ursula Kaiser and Ken Ho, Pituitary Physiology and Diagnostic Evaluation. Williams Textbook of Endocrinology 8, 184-235.e14 (2020)

9. H.S. Andreas Barthel, M. Willenberg, S.R. Gruber, Bornstein:, J. Larry, Adrenal Insufficiency. Endocrinology: Adult and Pediatric Seventh Edition Jameson. MD, PhD. Chapter 102, 1763-1774.e7 (2016)

10. D.C. John, R.J. Newell-Price, Auchus, The Adrenal Cortex. Williams textbook of endocrinology, 14th edn. (Saunders. Elsevier, Philadelphia, 2020), pp. 480-541

11. S.K. Mishra, N. Gupta, R. Goswami, Plasma adrenocorticotropin (ACTH) values and cortisol response to 250 and 1 microg ACTH stimulation in patients with hyperthyroidism before and after carbimazole therapy: case-control comparative study. J. Clin. Endocrinol. Metab. 92, 1693-1696 (2007)

12. K. Agbaht, S. Gullu, Adrenocortical reserves in hyperthyroidism. Endocrine 45(1), 136-143 (2014)

13. N. Yamakita, T. Murai, Y. Kokubo, M. Hayashi, A. Akai et al., Dehydroepiandrosterone sulphate is increased and dehydroepiandrosterone-response to corticotrophin-releasing hormone is decreased in the hyperthyroid state compared with the euthyroid state. Clin. Endocrinol. (Oxf) 55(6), 797-803 (2001)

14. A. Tsatsoulis, E.O. Johnson, C.H. Kalogera, K. Seferiadis, O. Tsolas, The effect of thyrotoxicosis on adrenocortical reserve. Eur. J. Endocrinol. 142(3), 231-235 (2000)

15. P. Moghetti, R. Castello, F. Tosi, M.G. Zenti, C. Magnani et al., Glucose counter-regulatory response to acute hypoglycemia in hyperthyroid human subjects. J Clin Endocrinol Metab. 78(1), 169-173 (1994)

16. S.O. Nascif, P. Molica, S.R. Correa-Silva, M.R. Silva, A.M. Lengyel, Ghrelin and GHRP-6-induced ACTH and cortisol release in thyrotoxicosis. Pituitary. 12(4), 315-321 (2009)

17. R.K. Boler, N.A. Moore, Depression of adrenal cortical functionby pharmacological doses of thyroxine in intact and unilaterallyadrenalectomized rats. Hormone Research. 16209-218 (1982)

18. M. Kawaguch, S. Iwata, Y. Kamiya, F. Hayakawa, T. Fujii, J. Ito et al., Thyroid storm associated with probable subclinical hypoadrenocortiscism in an elderly woman. Internal Medicine. 31, 1236-1238 (1992)

19. E.O. Johnson, A.E. Calogero, M. Konstandi, T.C. Kamilaris, S. La Vignera et al., Effects of experimentally induced hyperthyroidism on central hypothalamic-pituitary-adrenal axis function in rats: in vitro and in situ studies. Pituitary 16, 275-286 (2013) 
20. S.R. Bornstein, B. Allolio, W. Arlt, A. Barthel, A. Don-Wauchope et al., Diagnosis and Treatment of Primary Adrenal Insufficiency: An Endocrine Society Clinical Practice Guideline. The Journal of Clinical Endocrinology \& Metabolism 101(2), 1 February, Pages 364-389 (2016)

21. O. Chabre, B. Goichot, D. Zenaty, J. Bertherat, Group 1. Epidemiology of primary and secondary adrenal insufficiency: Prevalence and incidence, acute adrenal insufficiency, long-term morbidity and mortality. Ann Endocrinol (Paris) 78(6), 490-494 (2017)

22. W.A. Scherbaum, P.A. Berg, : Development of adrenocortical failure in non- Addisonian patients with antibodies to adrenal cortex. A clinical follow-up study. Clin. Endocrinol. (Oxf) 16, 345-352 (1982)

23. M. Skamagas, E.B. Geer, Autoimmune hyperthyroidism due to secondary adrenal insufficiency: resolution with glucocorticoids. Endocr Pract. 17(1), 85-90 (2011)

24. K. Tordjman, A. Jaffe, Y. Trostanetsky, Y. Greenman, R. Limor et al., Low-dose (1 microgram) adrenocorticotrophin (ACTH) stimulation as a screening test for impaired hypothalamo-pituitaryadrenal axis function: sensitivity, specificity and accuracy in comparison with the high-dose (250 microgram) test. Clin. Endocrinol. (Oxf) 52(5), 633-640 (2000)

\section{Tables}

Table-1: Comparison of demographic features and biochemical measurements between patients with differentiated thyroid cancer and healthy control group. 


\begin{tabular}{|llll|}
\hline & $\begin{array}{l}\text { Differentiated thyroid } \\
\text { cancer patients }(\mathbf{n = 5 5})\end{array}$ & $\begin{array}{l}\text { Healthy control group } \\
(\mathbf{n}=32)\end{array}$ & $p$ \\
\hline Age & $44.27 \pm 10.81$ & $42.65 \pm 13.79$ & 0.546 \\
\hline $\begin{array}{l}\text { Gender } \\
\text { Female }\end{array}$ & $50(90.9 \%)$ & $27(84.4 \%)$ & 0.357 \\
\hline Male & $5(9.1 \%)$ & $5(15.6 \%)$ & \\
\hline BMI (kg/m $)$ & $27.02 \pm 3.75$ & $25.79 \pm 3.82$ & 0.138 \\
\hline Fasting glucose (mg/dl) & $91.2 \pm 9.46$ & $94.03 \pm 11.01$ & 0.229 \\
\hline ALT (U/L) & $19.49 \pm 9.19$ & $21.50 \pm 12.33$ & 0.251 \\
\hline Trigliserid (mg/dl) & $143.23 \pm 87.16$ & $122.34 \pm 54.11$ & 0.172 \\
\hline LDL (mg/dl) & $111.29 \pm 30.14$ & $114.38 \pm 46.38$ & 0.707 \\
\hline HDL (mg/dl) & $59.59 \pm 29.03$ & $52.03 \pm 13.98$ & 0.597 \\
\hline fT3 (pg/mL) & $3.29 \pm 0.55$ & $3.13 \pm 0.40$ & 0.140 \\
\hline fT4 (ng/dL) & $1.87 \pm 0.32$ & $1.23 \pm 0.20$ & $<0.001$ \\
\hline TSH (ulU/mL) & $0.07 \pm 0.11$ & $2.11 \pm 1.00$ & $<0.001$ \\
\hline Basal cortisol (mcg/dl) & $12.14 \pm 5.12$ & $18.00 \pm 5.56$ & $<0.001$ \\
\hline Low basal cortisol (<14.5 & $34(61.8 \%)$ & & $10(31.3 \%)$ \\
\hline mcg/dL) & $21.49 \pm 11.77$ & - & 0.006 \\
\hline ACTH (ng/L) & & & - \\
\hline
\end{tabular}

BMI: body mass index, ALT: alanine aminotransferase, LDL: low-density lipoprotein, HDL: high-density lipoprotein, fT3:free triiodothyronine, fT4: free thyroxine, TSH: Thyroid-stimulating hormone, ACTH: adrenocorticotropic hormone

Table-2: Clinical and laboratory features of two differentiated thyroid cancer patients who did not respond to the adrenocorticotropin stimulation test 


\begin{tabular}{|lll|}
\hline & Case-1 & Case-2 \\
\hline Age (year) / Gender & 59 / Female & 47 / Female \\
\hline The duration of suppression (months) & 43 & 40 \\
\hline Basal hormone levels & & \\
Cortisol (mcg/dl) & 8.1 & 11.7 \\
ACTH (ng/L) & 23.0 & 14.3 \\
Cortisol response after ACTH stimulation test & & \\
0. min cortisol (mcg/dl) & & \\
30. min cortisol (mcg/dl) & 8.3 & 4.8 \\
60. min cortisol (mcg/dl) & 14.2 & 14.8 \\
& 17.1 & 17.6 \\
\hline
\end{tabular}

ACTH: adrenocorticotropic hormone

Table 3: Comparison of basal cortisol and adrenocorticotropic hormone levels according to the duration of thyrotrophin suppression in differentiated thyroid cancer patients with a basal cortisol level of $<14.5$ $\mathrm{mcg} / \mathrm{dL}$

\begin{tabular}{|llllr|}
\hline & $\begin{array}{l}\text { All patients } \\
(n=34)\end{array}$ & $\begin{array}{l}\text { Duration of suppression }<5 \\
\text { years }(\mathrm{n}=22)\end{array}$ & $\begin{array}{l}\text { Duration of suppression } \\
\geq 5 \text { years }(\mathrm{n}=12)\end{array}$ & $\boldsymbol{p}$ \\
\hline $\begin{array}{l}\text { Basal cortisol } \\
(\mathrm{mcg} / \mathrm{dL})\end{array}$ & $8.95 \pm 2.76$ & $9.48 \pm 2.65$ & $7.46 \pm 2.63$ & 0.022 \\
\hline $\begin{array}{l}\text { Basal ACTH } \\
(\mathrm{ng} / \mathrm{L})\end{array}$ & $16.75 \pm 7.39$ & $17.42 \pm 7.79$ & $14.71 \pm 6.12$ & 0.320 \\
\hline
\end{tabular}

ACTH: adrenocorticotropic hormone

Table 4: Correlation between basal cortisol and adrenocorticotropic hormone levels, and clinical features and thyroid functions in differentiated thyroid cancer patients with a basal cortisol level of $<14.5 \mathrm{mcg} / \mathrm{dL}$ 


\begin{tabular}{|lllll|}
\hline & Cortisol & \multicolumn{3}{l|}{ ACTH } \\
\hline & $\boldsymbol{r}$ & $\boldsymbol{p}$ & $\boldsymbol{r}$ & $\boldsymbol{p}$ \\
\hline Levothyroxine weekly dose & -0.153 & 0.388 & 0.272 & 0.120 \\
\hline RAl dose & 0.023 & 0.896 & 0.276 & 0.114 \\
\hline TSH & 0.122 & 0.494 & 0.050 & 0.777 \\
\hline fT4 & 0.282 & 0.106 & 0.208 & 0.237 \\
\hline fT3 & 0.268 & 0.125 & $-\mathbf{0 . 3 5 8}$ & $\mathbf{0 . 0 3 8}$ \\
\hline
\end{tabular}

ACTH: adrenocorticotropic hormone, RAl: radioactive iodine, TSH: thyroid-stimulating hormone, fT4: free thyroxine, fT3: free triiodothyronine, 